Article

\title{
Evaluation of the Explosion Pressure Parameters in Flameproof Enclosures under the Pressure Piling Condition
}

\author{
Dong $\mathrm{Li}^{1,2}$, Shijie Dai ${ }^{1, *}$ and Tao $\mathrm{Lin}^{3}$ \\ 1 School of Mechanical Engineering, Hebei University of Technology, Tianjin 300401, China; \\ lidong16@cnooc.com.cn \\ 2 CNOOC Tianjin Chemical Research \& Design Institute Ltd., Tianjin 300131, China \\ 3 School of Artificial Intelligence, Hebei University of Technology, Tianjin 300401, China; lintao@hebut.com.cn \\ * Correspondence: dsj@hebut.edu.cn; Tel.: +86-22-2668-9240
}

Citation: Li, D.; Dai, S.; Lin, T.

Evaluation of the Explosion Pressure Parameters in Flameproof Enclosures under the Pressure Piling Condition. Energies 2021, 14, 8156. https:// doi.org/10.3390/en14238156

Academic Editor: Giorgio Vilardi

Received: 29 September 2021

Accepted: 29 November 2021

Published: 5 December 2021

Publisher's Note: MDPI stays neutral with regard to jurisdictional claims in published maps and institutional affiliations.

Copyright: (c) 2021 by the authors. Licensee MDPI, Basel, Switzerland. This article is an open access article distributed under the terms and conditions of the Creative Commons Attribution (CC BY) license (https:// creativecommons.org/licenses/by/ $4.0 /)$.

\begin{abstract}
Explosion resistance is one of the most important performances for all flameproof enclosures. Pressure piling requires the flameproof enclosures to withstand explosion pressure higher than the design pressure. In order to study the explosion parameters in a flameproof enclosure under pressure piling, two experimental setups were prepared based on the theoretical analysis of the mechanism of pressure piling. One setup simulated the condition that the interior of a flameproof box is isolated by a baffle with a small hole. Another setup simulated the condition that a large number of electrical components were installed inside an explosion-proof box. The experimental result showed that the explosion pressure increased significantly in a very short time under pressure piling. When an explosion occurred in a cavity, the pressure wave of the explosion propagated faster than the flame propagation, and the pressure wave was transmitted to another cavity through a gas channel between the two cavities. This resulted in the pre-pressurization of the combustible gas in another cavity. It was observed that the ignition time in the cavity with an ignition source, is the key factor for pressure piling.
\end{abstract}

Keywords: explosion resistance; pressure piling; gas channel

\section{Introduction}

Substances with flammable and explosive characteristics can easily form an explosive environment in the process of mining, oil, and gas development, and transportation. In particular, most of the production facilities in the petrochemical industry are installed in an explosive gas atmosphere [1]. Flameproof electrical equipment is widely used in an explosive gas atmosphere to prevent the ignition of surrounding flammables. Figure 1a shows a photo of a flameproof control box after an explosion and Figure $1 \mathrm{~b}$ shows a photo of the upper-end cover of the flameproof control box after this explosion. The cause of this accident was the following. Due to flammable gas leakage, when the concentration of the flammable gas in the chamber was within the explosion limit, a spark generated by the start button ignited the flammable gas and it exploded, as shown in Figure 1c. As the flameproof control box was divided into two cavities, as shown in Figure 1d, pressure piling occurred. The explosion pressure exceeded the designed pressure of the shell. As is well known, explosion resistance is an important attribute to determine the performance of flameproof electrical equipment. The enclosure needs to have a certain level of mechanical strength so that any internal explosion will not cause enclosure damage or deformation. Enclosures should be well designed and carefully used as much as possible to avoid the pressure piling. However, pressure piling is normally not taken into consideration in the process of equipment design and installation. The explosion pressure will cause enclosure damage or deformation. 


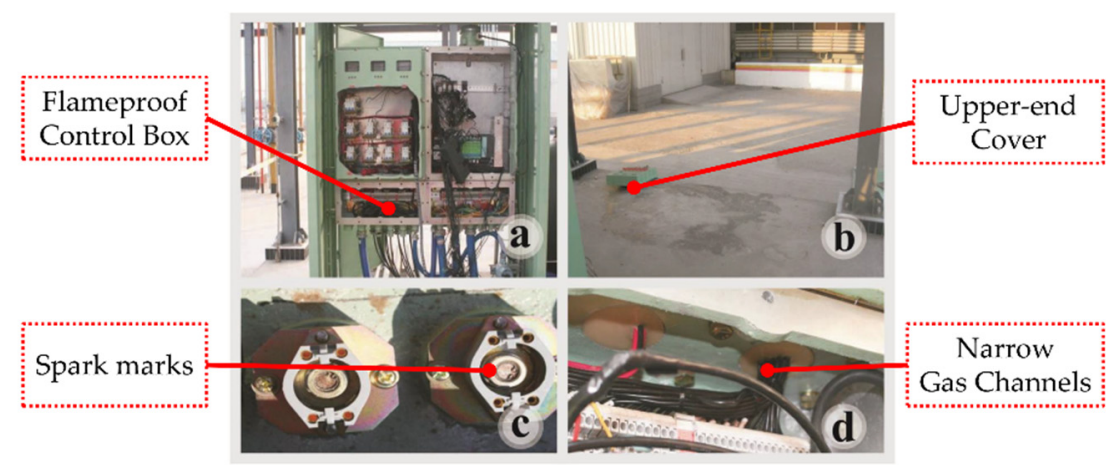

Figure 1. Burst accident of flameproof electrical equipment.

Pressure piling is defined as "results of an ignition, in a compartment or subdivision of an enclosure, of a gas mixture recompressed, for example, due to a primary ignition in another compartment or subdivision" [2]. Therefore, the evaluation of the explosion pressure parameters in flameproof enclosures under the pressure piling condition plays a significant role in the industry.

Researchers have done a lot of studies on the flameproof enclosure from the points of design and test and such studies have established the foundation for practical applications. In the industry, the strength designing of flameproof enclosures is usually carried out according to theoretical calculations. With the development of computer technology, using ANSYS, the finite element model for flameproof enclosures, can be conveniently established and various loads can be applied to understand the deformation and stress of structures [3]. However, a test for demonstrating the ability of the enclosure to withstand the pressure is very important for flameproof enclosures. The objective of the test is to verify that the enclosure can withstand the pressure of an internal explosion [4]. Tim et al. investigated the static and dynamic stresses of flameproof enclosures [5]. It was shown that the results obtained under these two conditions were different. In the ability test of an enclosure to withstand the pressure, the temperature, the ignition source position, and obstacles in the flameproof enclosure have significant effects on the development of the pressure $[6,7]$. However, the internal structure of enclosures can also affect the explosion pressure in practical industrial applications.

In recent years, because of frequent pipeline explosion accidents, an explosion in pipelines has become the focus of research. A series of experiments were carried out in a spherical vessel connected to a pipeline. The results showed that the presence of obstacles, the blockage ratio, and the position play significant roles in determining the explosion intensity [8]. The explosion severity can be very high in the turbulent field of methane/air mixture and the presence of strong ignition energies [9]. When two spherical vessels are connected by a pipe, the peak pressure and the rate of pressure rise are much higher than those observed in single vessel explosions [10-12]. The maximum explosion pressure and the rate of pressure rise increase when a small vessel is used as the secondary vessel [13]. These studies on pressure piling mainly focused on theory and simulation [14,15].

In the above studies, the research target was mainly limited to coal mine methane gas, and the experimental setups were prepared just by connecting pipes and vessels. However, petrochemical facilities are located in an explosive gas environment, and explosion-proof equipment is mostly used. The pressure piling can also occur if flameproof enclosures are not well designed or installed correctly. In this article, the theoretical analysis of pressure piling was carried out by using some fundamental equations firstly. Then, the situations encountered in actual industrial applications were reproduced by preparing two experimental setups. Through the experimental research, the theoretical analysis was verified and the relevant requirements in the standard were proven to be satisfied. 


\section{Theory of the Pressure Piling}

It is assumed that the pressure piling occurs when either of the following conditions will be met [4].

(1) The ratio between the pressures at the ignition side and the opposite side, obtained during a series of experiments under the same configuration, is higher than 1.5, or

(2) The pressure rise time is less than five $\mathrm{ms}$.

In the ideal state, the explosion pressure after the explosion of the combustible gas mixture can be determined according to the ideal gas law that the explosion pressure is proportional to the temperature before and after the explosion, the initial pressure, and the number of moles before and after the explosion. The ideal gas law can be expressed as follows [16]:

$$
\frac{p_{m}}{p_{0}}=\frac{T_{m}}{T_{0}} \times \frac{n_{m}}{n_{0}}
$$

where $p_{m}$ is the maximum explosion pressure of the gas, $p_{0}$ is the initial pressure of the gas, $T_{m}$ is the maximum temperature of the gas after the explosion, $T_{0}$ is the initial temperature of the gas, $n_{m}$ is the number of moles of gas after the explosion, and $n_{0}$ is the number of moles of the gas before the explosion.

By transforming Equation (1), the pressure of the gas after the explosion can be calculated by the following equation.

$$
p_{m}=\frac{T_{m} n_{m}}{T_{0} n_{0}} p_{0}
$$

The degree of damage to the equipment during an explosion is not only related to the maximum explosion pressure but also the rate of explosion pressure rise. The explosion power index is used to express the degree of explosion damage.

$$
E_{p}=p_{m} \times v
$$

where $E_{p}$ is the explosion pressure index and $v$ is the average pressure rise rate determined by the following equation:

$$
v=\frac{p_{m}-p_{0}}{t}
$$

where $t$ is the pressure rise time.

After transforming Equations (2)-(4), we can obtain the following equation:

$$
E_{p}=\frac{\left(\frac{T_{m} n_{m}}{T_{0} n_{0}} p_{0}\right)^{2}-\frac{T_{m} n_{m}}{T_{0} n_{0}} p_{0}^{2}}{t}
$$

The key parameter of the pressure piling can be derived from Equation (5). When an explosion occurs in a cavity, the pressure wave of the explosion propagates faster than the flame propagation, and the pressure wave is transmitted to another cavity through a gas channel between the two cavities [11]. An increase in the initial pressure $p_{0}$ in the cavity causes an increase in the pressure $p_{m}$ after the explosion, and the explosion pressure index $E_{p}$ also increases. The shorter the pressure rise time $t$ during the explosion is, the greater the explosion pressure index $E_{p}$ and the damage become.

\section{Experimental Platform}

\subsection{Experimental Device}

The explosion pressure test channel was added to meet the test requirement by using the existent explosion test device in our laboratory. The experimental device could achieve an online collection of the ternary gas distribution and the explosion pressure parameters. The experimental device consisted of a gas distribution system, an electric control system, an explosion tank, and a pressure acquisition system. The gas distribution system was 
used to control the concentration ratio between the combustible gas and air. The explosive tank was used to install the experimental samples, and the electric control system was used to control the gas distribution and ignition. The pressure acquisition system was composed of pressure sensors, charge amplifiers, and data acquisition systems. The pressure sensor is made of Piezoelectric Pressure Sensor (Kistler Type 6031, PE-250 bar /3'625 psi, Sensitivity-14 pC/bar/1.0 pC/psi, high inherent frequency-160 kHz). Charge amplification (Kistler Type 5018) is used for signal conditioning of piezoelectric pressure sensors to convert the charge signal of the sensor into a corresponding proportion of voltage output. For data acquisition and measurement, a PXI-5922 16 to 24-Bit digitizer coordinates (sampling rate $6 \mathrm{MHz}$ ) with the software is used. The schematic diagram of the experimental device is shown in Figure 2. The explosion pressure was determined by IEC 60079-1, section 15.2.2. The experimental flow chart is shown in Figure 3.

\subsection{Experimental Samples}

In industrial applications, it is very common that two chambers in a flameproof box are not isolated and sealed at the crossing line, such as flameproof enclosure with interconnected structure. The electrical components are installed inside a flameproof box because the shape and layout of the components cannot be changed. The interior of the enclosure was divided into two cavities with a gas channel, such as a motor. In this study, a flameproof enclosure, with interconnected structure and a motor, were used to reproduce the pressure piling condition.

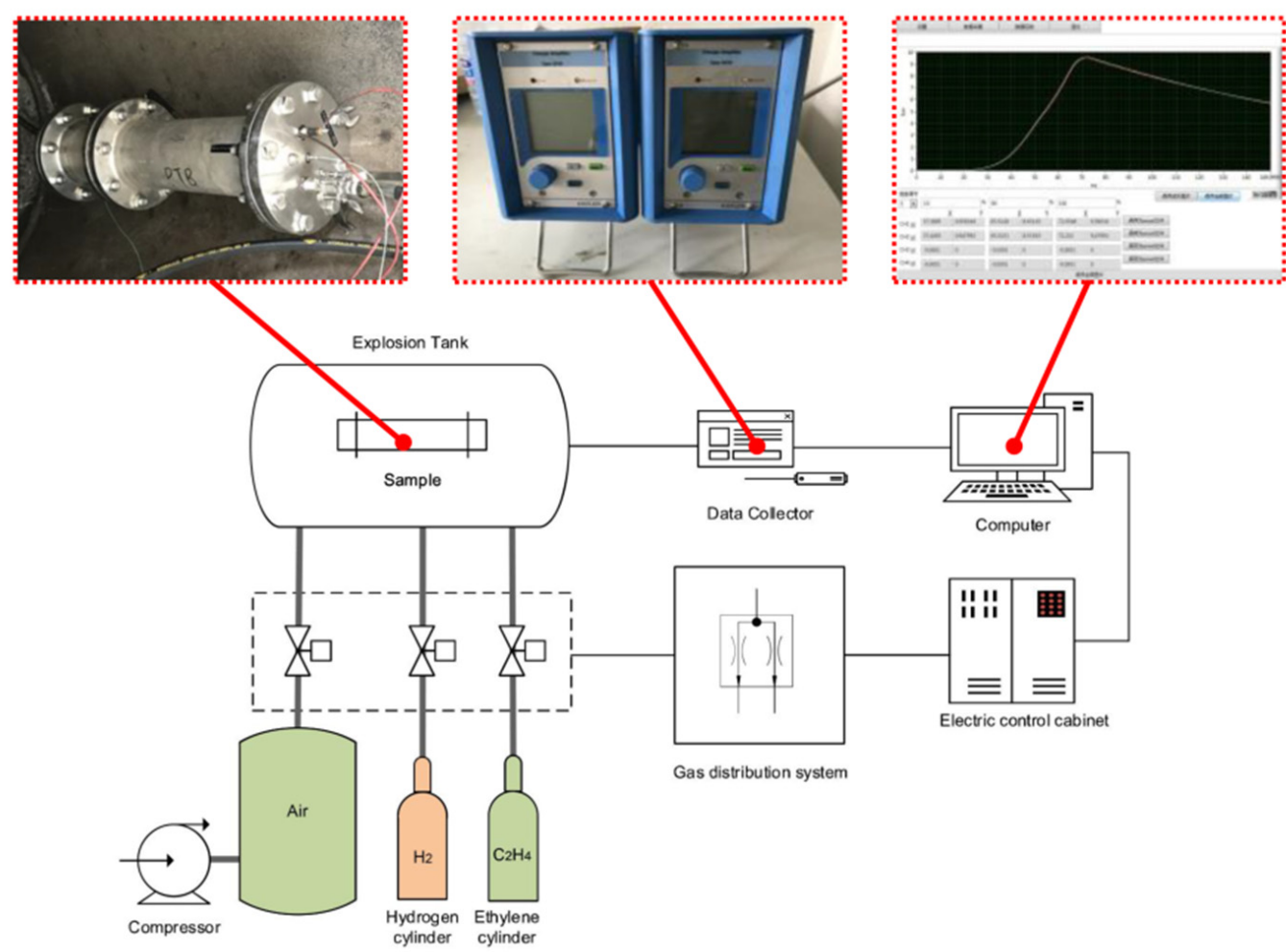

Figure 2. Schematic diagram of the experimental device. 


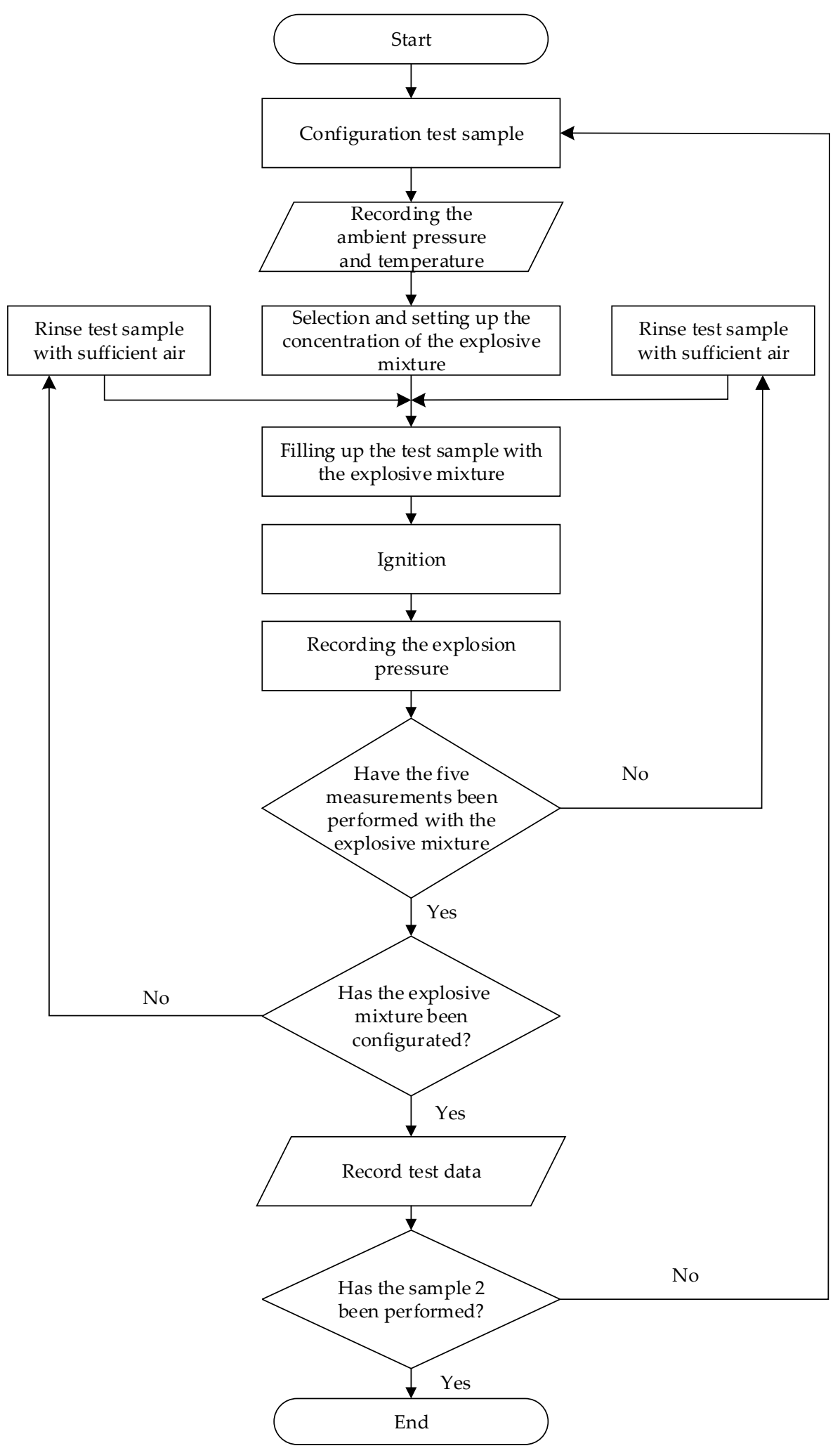

Figure 3. Experimental flow chart.

\subsubsection{Sample 1}

Sample 1 was composed of pipe A, pipe B, and an orifice, and the material of the sample is F304 L. The total lengths of pipes A and B were $250 \mathrm{~mm}$ and $500 \mathrm{~mm}$, respectively. The inner diameter of the cavity was $161.5 \mathrm{~mm}$, while that of the middle hole in the orifice was $15 \mathrm{~mm}$. The thickness of the orifice was $6 \mathrm{~mm}$. These three parts were connected by 
twenty-four M20X80 hexagonal bolts. Two M20X80 hexagonal bolts were connected with gaskets between the flanges. The net volumes of pipes A and B were about $5.12 \mathrm{~L}$ and $10.23 \mathrm{~L}$, respectively. The air source interface and the pressure sensor were installed on the flange of pipes $A$ and $B$ according to the thread specifications.

Configuration 1 consists of pipes A and B and the ignition source was installed on the flange of pipe A. Configuration 1 is shown schematically in Figure 4. Configuration 2 consists of pipe A, pipe B, and an orifice, and the ignition source was installed on the flange of pipe A. Configuration 2 is shown schematically in Figure 5.

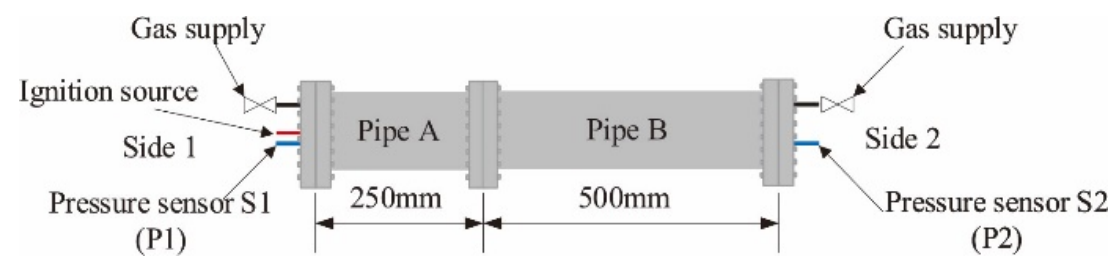

Figure 4. Configuration 1 of sample 1.

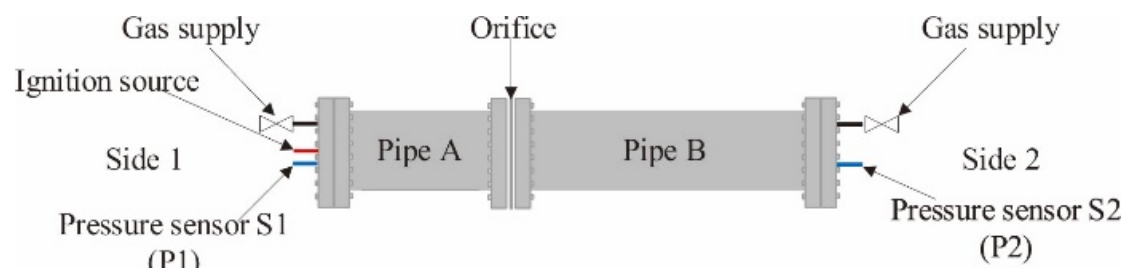

Figure 5. Configuration 2 of sample 1.

According to the experimental parameters and procedures, specified in IEC 60079-1, ethylene was selected as a typical explosive gas. The experimental conditions for Sample 1 are shown in Table 1.

Table 1. Experimental condition for Sample 1.

\begin{tabular}{ccccccc}
\hline Gas & $\begin{array}{c}\text { Molecular } \\
\text { Symbol }\end{array}$ & $\begin{array}{c}\text { Volume } \\
\text { Ratio }\end{array}$ & $\begin{array}{c}\text { Ambient } \\
\text { Humidity (\%) }\end{array}$ & $\begin{array}{c}\text { Ambient } \\
\text { Temperature }\left({ }^{\circ} \mathbf{C}\right)\end{array}$ & $\begin{array}{c}\text { Initial Pressure } \\
\text { (Bar) }\end{array}$ & Number of Trials \\
\hline Ethylene & $\mathrm{C}_{2} \mathrm{H}_{4}$ & $8 \pm 5 \%$ & $40 \pm 2$ & $20 \pm 5$ & 1.0 & 5 \\
\hline
\end{tabular}

\subsubsection{Sample 2}

A flameproof three-phase asynchronous motor was selected as Sample 2. The shape of the stator and the rotor shell of the motor was cylindrical. As the air gap between the stator and the rotor was very small, there was a narrow channel connecting the front and rear covers of the motor, as shown in Figure 6. Following the experimental procedure specified in IEC 60079-1 section 15.2.2.2, ethylene (volume ratio $=8 \pm 0.5 \%$ ) was selected as an explosive gas for the experiment. Sensors were set on both the front and back covers, and ignition was conducted from both ends. Five sets of experiments under the stationary and rotating states of the motor were performed alternately. The experimental conditions for Sample 2 are shown in Table 2. 


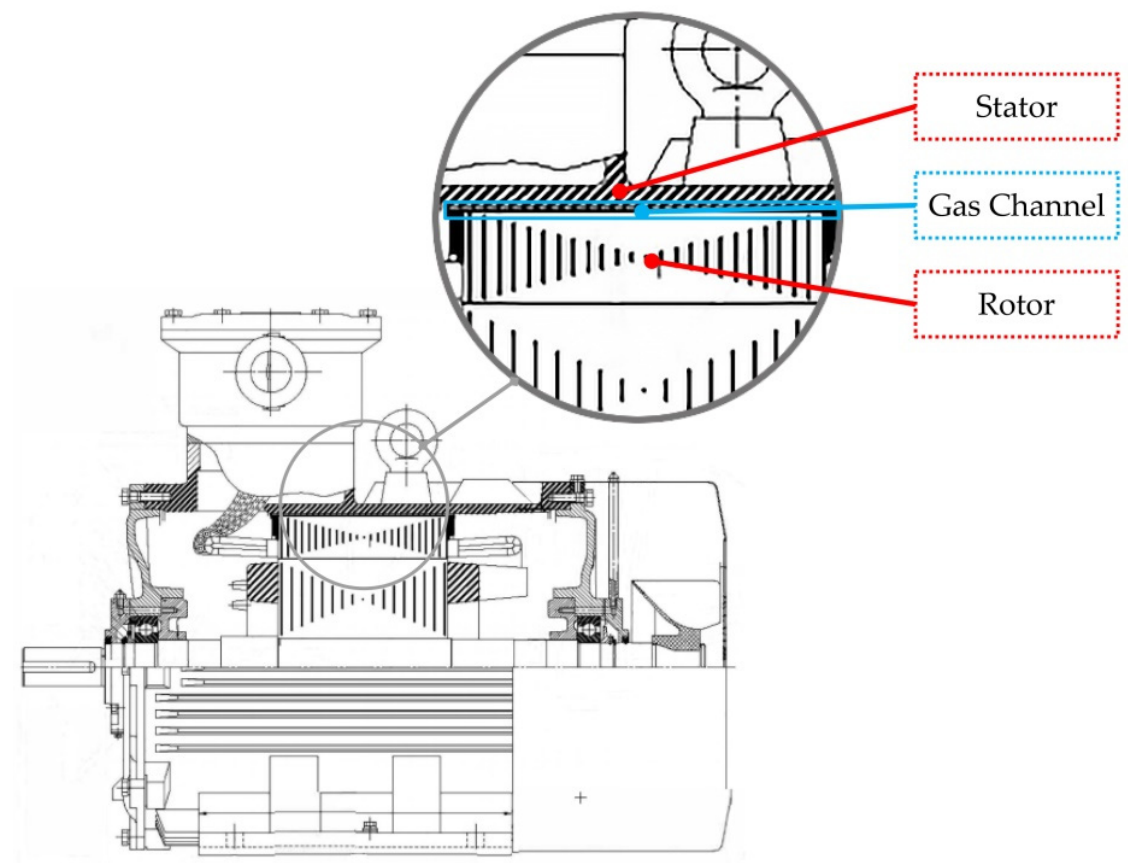

Figure 6. Schematic layout of Sample 2.

Table 2. Experimental condition for Sample 2.

\begin{tabular}{cccccccc}
\hline $\begin{array}{c}\text { Ignition } \\
\text { Position }\end{array}$ & Motor Status & $\begin{array}{c}\text { Pressure } \\
\text { Position 1 }\end{array}$ & $\begin{array}{c}\text { Pressure } \\
\text { Position 2 }\end{array}$ & $\begin{array}{c}\text { Ambient } \\
\text { Humidity (\%) }\end{array}$ & $\begin{array}{c}\text { Ambient } \\
\text { Temperature }\left({ }^{\circ} \text { C) }\right.\end{array}$ & $\begin{array}{c}\text { Initial } \\
\text { Pressure (bar) }\end{array}$ & $\begin{array}{c}\text { Number } \\
\text { of Trials }\end{array}$ \\
\hline Front cover & Rest & Front cover & Rear cover & $40 \pm 2$ & $20 \pm 5$ & 1.0 & 5 \\
Front cover & Running & Front cover & Rear cover & $40 \pm 2$ & $20 \pm 5$ & 1.0 & 5 \\
Rear cover & Rest & Front cover & Rear cover & $40 \pm 2$ & $20 \pm 5$ & 1.0 & 5 \\
Rear cover & Running & Front cover & Rear cover & $40 \pm 2$ & $20 \pm 5$ & 1.0 & 5 \\
\hline
\end{tabular}

\section{Results and Discussions}

The pressure-time profiles of configuration 1 and configuration 2 for sample 1 are shown in Figure 7. The pressure-time profiles for sample 2 are shown in Figure 8 . The pressure ratio was determined as the ratio of the pressure at the opposite side to the ignition pressure at the ignition side. The pressure rise time was determined as the time between $10 \%$ and $90 \%$ of the curve of the maximum value of the pressure. The maximum rate of explosion pressure rise $(d p / d t)_{\max }$ was determined as the ratio of the maximum explosion pressure to the rise time, according to the IEC 60079-1 section 15.2.2.4.

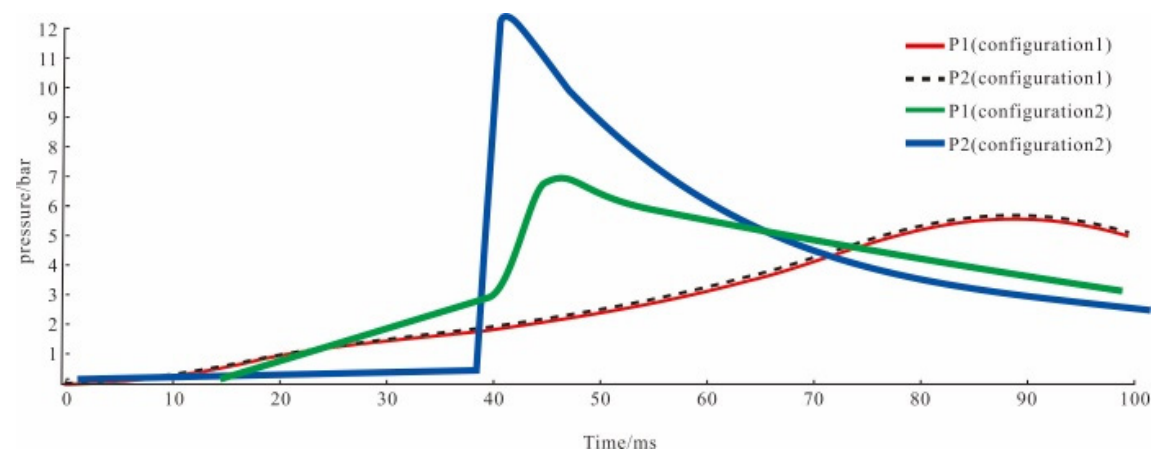

Figure 7. Pressure-time profile for sample 1 of configuration 1 and configuration 2. 


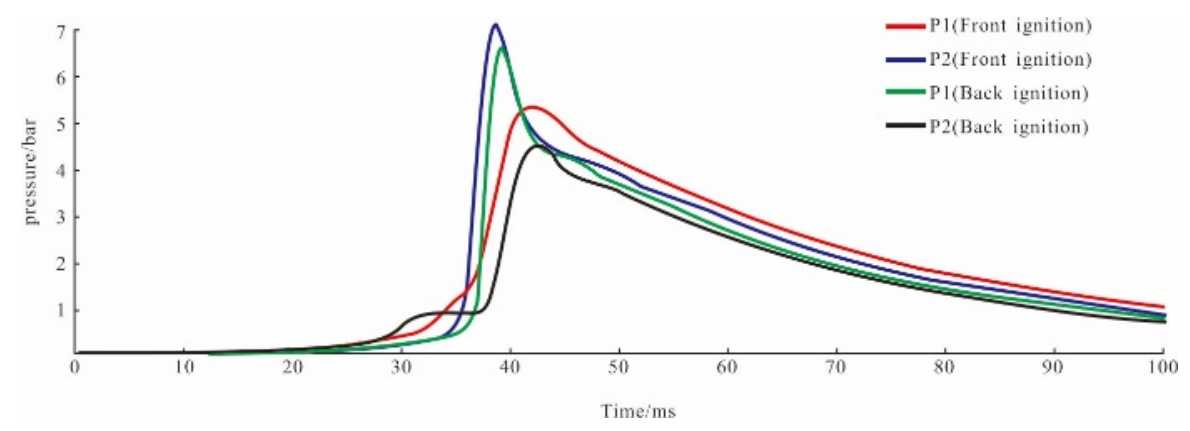

Figure 8. Pressure-time profile for sample 2.

The explosion parameters (the maximum explosion pressure, the pressure rise time, and the maximum rate of pressure rise) for sample 1 in five experiments are shown in Table 3. The explosion parameters (the maximum explosion pressure, the pressure rise time, and the maximum rate of pressure rise) for sample 2, in five experiments, are shown in Table 4.

Table 3. Explosion pressure parameters of sample 1.

\begin{tabular}{ccccccc}
\hline \multirow{2}{*}{ Sample } & \multicolumn{2}{c}{ The Maximum Explosion } & \multicolumn{2}{c}{ Pressure Rise Time (in ms) } & \multicolumn{3}{c}{ The Maximum Rate of } \\
& Pressure Value (in bar) & Pressure Rise (in bar/ms) \\
Side 1 & Side 2 & Side 1 & Side 2 & Side 1 & Side 2 \\
\hline Sample 1 (Configuration 1) & 5.67 & 5.80 & 64.41 & 64.32 & 0.09 & 0.09 \\
Sample 1 (Configuration 2) & 6.93 & 11.85 & 20.42 & 1.51 & 2.95 & 7.84 \\
\hline
\end{tabular}

Table 4. Explosion pressure parameters of sample 2.

\begin{tabular}{|c|c|c|c|c|c|c|}
\hline \multirow{2}{*}{ Ignition Place } & \multicolumn{2}{|c|}{$\begin{array}{l}\text { The maximum Explosion } \\
\text { Pressure Value (in bar) }\end{array}$} & \multicolumn{2}{|c|}{ Pressure Rise Time (in ms) } & \multicolumn{2}{|c|}{$\begin{array}{c}\text { The Maximum Rate of Pressure } \\
\text { Rise (in bar } / \mathrm{ms} \text { ) }\end{array}$} \\
\hline & Front Cover & Back Cover & Front Cover & Back Cover & Front Cover & Back Cover \\
\hline Front cover & 5.14 & 6.85 & 8.57 & 3.02 & 0.06 & 2.26 \\
\hline Rear cover & 6.08 & 4.12 & 2.23 & 11.85 & 2.73 & 0.35 \\
\hline
\end{tabular}

\subsection{Results of Sample 1}

For configuration 1, it can be seen, from Figure 7, that the pressure-time profiles of $\mathrm{P} 1$ and P2 are similar. It can be seen, from Table 3, that the maximum explosion pressures value at side 1 was 5.67 bar while that at side 2 was 5.80 bar, the pressure rise time at side 1 was $64.41 \mathrm{~ms}$, while that at side 2 was $64.32 \mathrm{~ms}$, and the maximum rate of pressure rise of side 1 and side 2 are same. The mixture of ethylene and air is ignited in a finite volume and reacts at an extremely fast rate of heat release, accumulating in a very short period of time in a finite volume, resulting in high temperature and high pressure, which creates an explosion pressure.

According to the ideal gas equation, the explosive pressure value is linearly related to the initial pressure value under the condition of the initial temperature and flammability gas determination. It can be seen that the factors that form the explosion pressure can be approximately equal, the initial pressure is approximately equal. It can be seen from Table 3 that the pressure ratio is 1.02 less than 1.5, the pressure rise time is $64.32 \mathrm{~ms}$ more than $5 \mathrm{~ms}$, according to IEC 60079-1, section 15.2.2, pressure piling did not occur.

For configuration 2 , it can be seen, from Table 3 , that the maximum explosion pressures value at side 1 was 6.93 bar, while that at side 2 was 11.85 bar, the pressure ratio was 1.71 more than 1.50, explosion-proof equipment is designed with a safety factor of 1.5 , and the explosion pressures value at side 2 was higher than the design pressure. The pressure rise time at side 1 was $20.42 \mathrm{~ms}$ while that at side 2 was $1.51 \mathrm{~ms}$, the maximum rate of pressure 
rise of side 1 was 2.95 , while that at side 2 was 7.84 , the pressure rise time was less than 5 ms. According to IEC 60079-1, section 15.2.2, pressure piling did occur.

To explain this phenomenon, we used ANSYS for numerical simulations. SolidWorks was used to establish a 1:1 3D model of flameproof enclosure, and then, the model was imported into ICEM for boundary layer meshing, and a finite element analysis model of flameproof enclosure was obtained (see Figure 9a). The numerical solution was performed in FLUENT software. Figure $9 \mathrm{~b}$ showed the physical model. The Initial conditions are shown in Table 1. The ignition source temperature was $400 \mathrm{~K}$, and the ignition was performed under the test conditions.

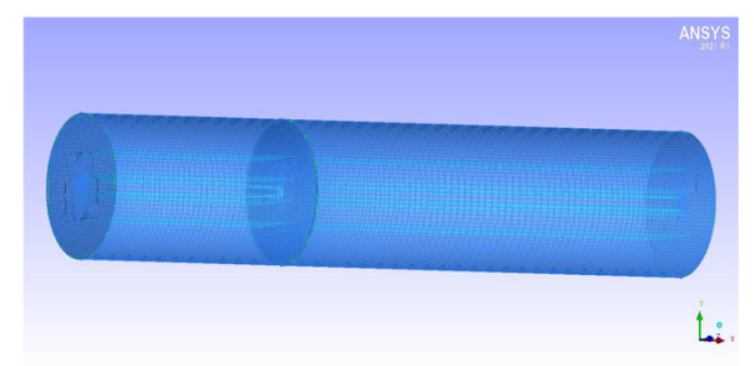

(a)

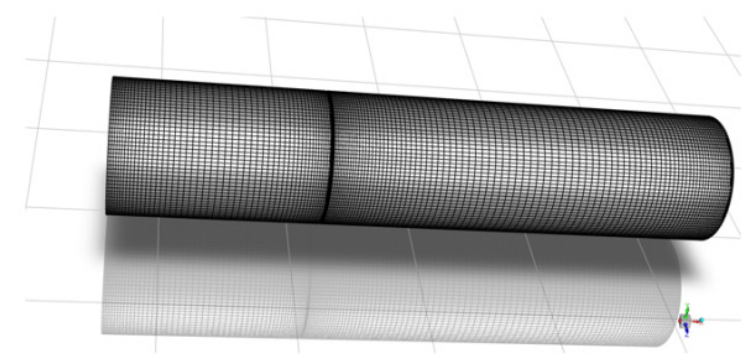

(b)

Figure 9. (a) Mesh generation for sample 1, (b) Physical model for sample 1.

According to the physical phenomenon of the explosion reaction process, combustible gas explosion fluid flow needed to be described by momentum equation, and the velocity field and pressure field distribution were calculated by solving the momentum conservation equation in spatial 3D model. In addition, due to the large temperature difference during the explosion, the effect of radiation on heat transfer must be considered, as well as the DO discrete coordinate system radiation model, which was widely used for explosion reaction was selected. The governing equations used for numerical calculations were the mass conservation equation, the momentum conservation equation, the energy conservation equation, the radiation model equation, the turbulence equation, and the component transport and reaction (explosion) model equation.

In order to take into account the influence of diffusion of turbulent components on the reaction, a very accurate conceptual model of eddy dissipation was chosen for the explosion reaction model.

Distribution of temperature field and explosion pressure field were shown in Figure 10. Figure 11 showed the explosion pressure wave form obtained by numerical simulation. After the flammable gas was ignited in cavity A, the flame spreads to cavity B in the form of a turbulent flame, an explosion pressure wave traveled to pipe B through a small hole between the two pipes, cavity B was not yet burned, and the initial pressure on cavity $\mathrm{B}$ was greater than the standard atmospheric pressure, so it can be concluded that the pressure wave of the explosion propagated faster than the flame propagation. The explosive pressure wave reached pipe B before the combustion flame reached. This resulted in the pre-pressurization of the combustible gas in pipe B [11]. when the flame spread to the small hole, the flammable gas in cavity B is ignited in a spray shape, and the flammable gas in 
cavity B was quickly ignited, while the flammable gas in cavity A had not yet fully burned, and the explosive pressure on the A side of the cavity was still increasing.

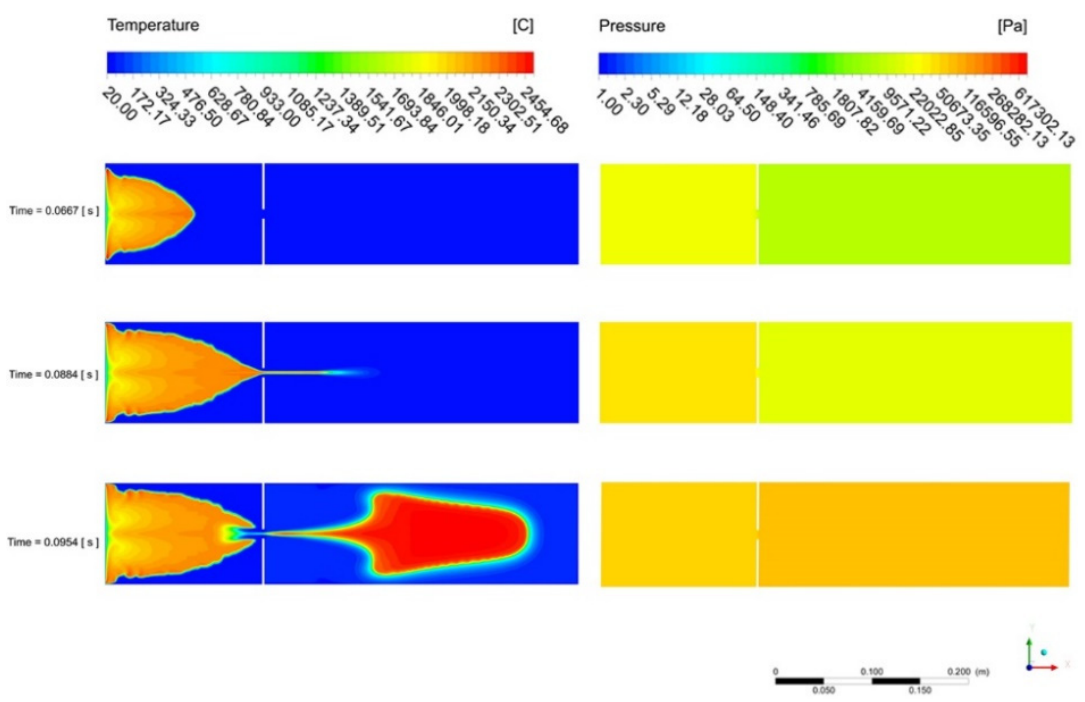

Figure 10. Distribution of temperature field and explosion pressure field.

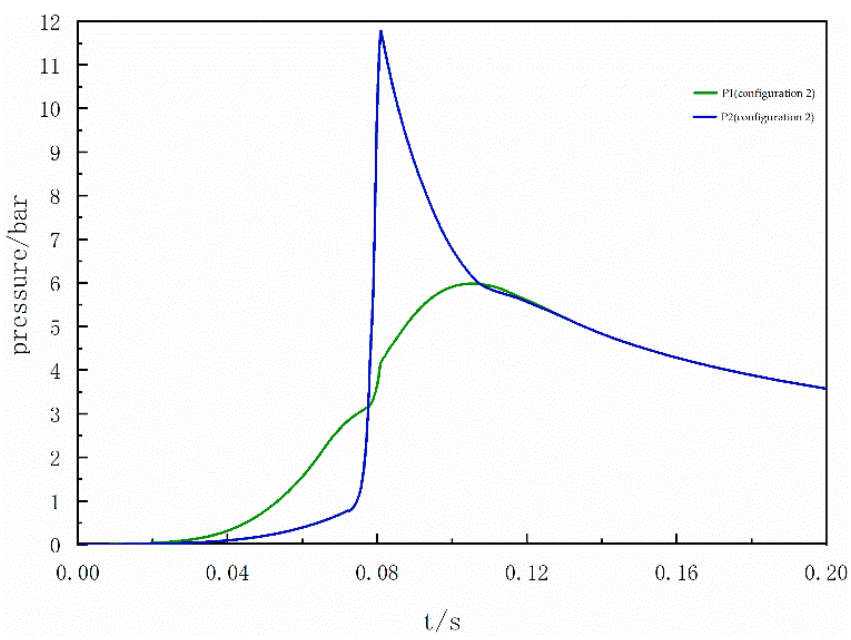

Figure 11. Waveform of explosion pressure of simulation.

The increase in the initial pressure $\mathrm{P} 0$ in pipe $\mathrm{B}$ causes an increase in the pressure Pm after the explosion, the explosion pressures value at side 2 was higher than that at side 1 . It can be also seen, from Figures 7 and 11, that pipe B reached the maximum explosion pressure earlier than the ignition source side and the value of the maximum rate of pressure rise on the opposite side was larger than that on the ignition source side. The maximum rate of pressure rise of side 2 increases and the explosion pressure index $E_{P}$ also increases. The shorter the pressure rise time $t$ during the explosion, the greater the explosion pressure index $E_{P}$ and the damage become.

From the perspective of the entire explosion process, an increase in explosion pressure in flameproof enclosure under pressure piling was due to the increase in initial pressure. After combustible gas was ignited in one cavity, as it exploded, the explosion pressure wave caused the initial pressure in the other cavity to increase in the equivalent of a constant volume change. The mechanism was consistent with the ideal gas equation of state.

The two chambers in the flameproof box were not isolated and sealed at the crossing line, and the interior of the enclosure was divided into two cavities by a narrow gas channel, 
which constituted a sufficient condition for the pressure piling. When two cavities must be connected, a flame-proof structure or a seal structure shall be designed.

\subsection{Results of Sample 2}

Table 4 shows the explosion pressure parameters of sample 2, and five sets of experiments under the stationary and rotating states of the motor were performed alternately. It can be seen that the maximum explosion pressures value at front cover was 5.14 bar, while that at back cover was $6.85 \mathrm{bar}$, and the explosion pressure ratios were less than 1.5, while the pressure rise time of back cover was less than $5 \mathrm{~ms}$. When the front cover is ignited, the maximum explosion pressures value at front cover was 6.08 bar, while that at back cover was 4.12 bar, the explosion pressure ratios was less than 1.5 , while the pressure rise time of front cover is less than $5 \mathrm{~ms}$ when the rear cover is ignited.

Figure 8 shows the pressure-time profile for sample 2 when the ignition was done in the front and back covers. It can be seen that, after ignition, the first explosion occurred in the cavity near the ignition source side in a very short time, and a shock wave was generated. Passing through the air gap between the rotor and the stator, the shock wave reached the opposite side before the combustion flame reached. This caused the explosive mixture in the opposite side, having a pre-pressure, to attain the maximum explosion pressure in a very short time. It can also be seen that the opposite side reached the maximum explosion pressure earlier than the ignition source side, and the value of $(d p / d t)_{\max }$ on the opposite side was larger than that on the ignition source side. The flame reached the opposite side under the action of a blast shock wave, and the opposite side was ignited before the value of Pm on the ignition source side (the value of $(d p / d t)_{\max }$ of the ignition source side $\neq 0$ ). Then the pressure piling occurred.

The stator of the motor is cylindrical, the inner rotor is made up of cylinders that cannot change, and the narrow gas channel between the rotor and the stator connects the cavity between the front and rear end cover and the rotor, which also constituted a sufficient condition for the pressure piling.

From the above experiments, we can see that the electrical components inside flameproof enclosures should be properly laid out. If not, they will create a narrow gas channel at both sides in the flameproof enclosure. It will constitute a sufficient condition for the pressure piling. When this kind of component layout cannot be avoided, the shell shall be designed to have increased explosion resistance.

\subsection{The Essence of the Pressure Pilling}

The pressure wave of the explosion propagated faster than the flame propagation. The two cavities were connected by small holes, so once an explosion occurred in one cavity, the flame traveled another cavity within the action time of one explosion pressure wave, the mixture of explosive gases and air in another compressed cavity was ignited immediately, and it caused the explosion pressures value to grow higher.

\section{Conclusions}

In this paper, a flameproof pipeline product and a flameproof three-phase asynchronous motor were used as samples to experimentally investigate the explosion pressure parameters during the pressure piling. From the experimental analysis and research, we can conclude as follows:

(1) A significant increase in the explosion pressure was observed in the flameproof enclosures. The pressure on the opposite side was much higher than that on the ignition side.

(2) The rise time of the explosion pressure in the flameproof enclosures was very short, and the pressure in the opposite enclosure reached the maximum value within a few milliseconds. 
(3) For a flameproof enclosure, if the interior of the enclosure is divided into cavities with narrow gas channels, this configuration constitutes a sufficient condition for the pressure piling.

(4) When the opposite side is ignited before the value of Pm on the ignition source side (the value of $(d p / d t)_{\text {max }}$ on the ignition source side $\left.\neq 0\right)$, the pressure piling occurs.

(5) Flameproof enclosures should be designed to have a flame-proof structure for avoiding the occurrence of the pressure piling.

(6) The shell shall be designed to have increased explosion resistance when the layout of the interior components cannot be changed.

(7) Without reassessment, the layout of the internal components of equipment shall not be changed because any careless changes may cause the pressure piling.

Author Contributions: Conceptualization, D.L.; methodology, D.L.; software, D.L.; validation, S.D.; formal analysis, D.L.; investigation, D.L.; resources, D.L.; data curation, D.L.; writing—original draft preparation, D.L.; writing—review and editing, D.L.; visualization, T.L.; supervision, D.L.; project administration, D.L.; funding acquisition, D.L. All authors have read and agreed to the published version of the manuscript.

Funding: This research was funded by CNOOC Energy Technology \& Services Limited, grant number TJY-2020-FB-01.

Institutional Review Board Statement: Not applicable.

Informed Consent Statement: Not applicable.

Data Availability Statement: The study did not report any data.

Acknowledgments: The authors would like to thank all the reviewers who participated in the review and MJEditor (www.mjeditor.com, accessed on 29 September 2021) for its linguistic assistance during the preparation of this manuscript.

Conflicts of Interest: The authors declare no conflict of interest.

\section{Nomenclature}

$\begin{array}{ll}(\text { do } / d t)_{\max } & \text { maximum rate of explosion pressure rise in bar } / \mathrm{ms} \\ E_{P} & \text { explosion pressure index } \\ n_{m} & \text { number of moles of gas after explosion, in mole } \\ n_{0} & \text { number of moles of gas before the explosion. } \\ P_{1} & \text { maximum explosion pressure on side } 1 \text { in bar } \\ P_{2} & \text { maximum explosion pressure on side2 in bar } \\ P_{m} & \text { maximum pressure in bar } \\ P_{0} & \text { initial pressure in bar } \\ T_{m} & \text { maximum temperature after the explosion in } \mathrm{K} \\ T_{0} & \text { initial temperature in } \mathrm{K} \\ t & \text { pressure rise time in } \mathrm{ms} \\ v & \text { average pressure rise rate in bar } / \mathrm{ms}\end{array}$

\section{References}

1. International Electrotechnical Commission. Explosive Atmospheres-Part 10-1: Classfication of Areas-Explosive Gas Atmospheres; IEC: Geneva, Switzerland, 2015; pp. 15-18.

2. International Electrotechnical Commission. International Electrotechnical Vocabulary(IEV)-Part 426:Explosive Atmospheres; IEC: Geneva, Switzerland, 2020.

3. Ahirwal, B.; Prasad, R.; Kashyap, S.K.; Banerjee, G. Stress analysis due to internal explosion pressure of designed flameproof enclosure for hazardous area. Process Saf. Prog. 2019, 39, e12100. [CrossRef]

4. International Electrotechnical Commision. Explosive Atmospheres-Part 1: Equipment Protection by Flameproof Enclosures "d"; IEC: Geneva, Switzerland, 2014; pp. 48-59.

5. Krause, T.; Bewersdorff, J.; Markus, D. Investigations of static and dynamic stresses of flameproof enclosures. J. Loss Prevent. Proc. 2017, 49, 775-784. [CrossRef] 
6. Munro, J.; Xiaoguang, K.; Yingzhen, H. Pressure testing flameproof equipment intended for extremely low temperatures. J. Loss Prevent. Proc. 2017, 49, 769-774. [CrossRef]

7. Vishwakarma, R.K.; Ranjan, V.; Kumar, J. Comparison of explosion parameters for Methane-Air mixture in different cylindrical flameproof enclosures. J. Loss Prevent Proc. 2014, 31, 82-87. [CrossRef]

8. Zuo, Q.; Wang, Z.; Zhen, Y.; Zhang, S.; Cui, Y.; Jiang, J. The effect of an obstacle on methane-air explosions in a spherical vessel connected to a pipeline. Process Saf. Prog. 2016, 36, 67-73. [CrossRef]

9. Kundu, S.K.; Zanganeh, J.; Eschebach, D.; Mahinpey, N.; Moghtaderi, B. Explosion characteristics of methane-air mixtures in a spherical vessel connected with a duct. Process Saf. Environ. 2017, 111, 85-93. [CrossRef]

10. Maremonti, M.; Russo, G.; Salzano, E.; Tufano, V. Numerical simulation of gas explosions in linked vessels. J. Loss Prevent. Proc. 1999, 12, 189-194. [CrossRef]

11. Yan, C.; Wang, Z.R.; Jiao, F.; Ma, C. Numerical simulation on structure effects for linked cylindrical and spherical vessels. Simulation 2018, 94, 849-858. [CrossRef]

12. Wang, Z.; Pan, M.; Wang, S.; Sun, D. Effects on external pressures caused by vented explosion of methane-air mixtures in single and connected vessels. Process Saf. Prog. 2014, 33, 385-391. [CrossRef]

13. Zhang, K.; Wang, Z.; Jiang, J.; Sun, W.; You, M. Effect of pipe length on methane explosion in interconnected vessels. Process Saf. Prog. 2016, 35, 241-247. [CrossRef]

14. Di Benedetto, A.; Salzano, E.; Russo, G. Predicting pressure piling by semi-empirical correlations. Fire Saf. J. 2005, 40, 282-298. [CrossRef]

15. Di Benedetto, A.; Salzano, E. CFD simulation of pressure piling. J. Loss Prev. Proc. 2010, 23, 498-506. [CrossRef]

16. Zhen, Y.; Wang, Z.; Gong, J. Experimental study of the initial pressure effect on methane-air explosions in linked vessels. Process Saf. Prog. 2017, 37, 86-94. [CrossRef] 